\title{
Seroprevalence of Leptospirosis among Army Personnel in Northeastern Malaysia
}

\author{
Y. Siti Sara1, B. D. Aziah"²* (, Y. N. Azwany², S. Mohd Nazri², W. M. Zahiruddin², A. Nabilah³, \\ H. Siti Asma'3, I. Zaliha4, A. Fairuz ${ }^{5}$ \\ ${ }^{1}$ Public Health Division, Selangor State Health Department, Ministry of Health, Selangor, Malaysia \\ ${ }^{2}$ Department of Community Medicine, School of Medical Sciences, Universiti Sains Malaysia, Kelantan, Malaysia \\ ${ }^{3}$ Department of Medical Microbiology \& Parasitology, School of Medical Sciences, Universiti Sains Malaysia, Kelantan, Malaysia \\ ${ }^{4}$ Population Health \& Preventive Medicine Discipline, Faculty of Medicine, Universiti Teknologi MARA, Selangor, Malaysia \\ ${ }^{5}$ Institute for Medical Research (IMR), Kuala Lumpur, Malaysia \\ Email: *aziahkb@usm.my
}

How to cite this paper: Sara, Y.S., Aziah, B.D., Azwany, Y.N., Nazri, S.M., Zahiruddin, W.M., Nabilah, A., Asma', H.S., Zaliha, I. and Fairuz, A. (2020) Seroprevalence of Leptospirosis among Army Personnel in Northeastern Malaysia. Advances in Infectious Diseases, 10, 37-45.

https://doi.org/10.4236/aid.2020.101004

Received: February 12, 2020

Accepted: March 24, 2020

Published: March 27, 2020

Copyright (C) 2020 by author(s) and Scientific Research Publishing Inc. This work is licensed under the Creative Commons Attribution International License (CC BY 4.0).

http://creativecommons.org/licenses/by/4.0/

\section{(c) (i) Open Access}

\begin{abstract}
Leptospirosis is a zoonotic disease caused by pathogenic Leptospira. The disease affects various high-risk groups including army personnel, who are at risk because of field activities that bring them into close contact with zoonotic reservoirs. This cross-sectional study determined the seroprevalence of leptospirosis among 616 asymptomatic army personnel in Northeastern Malaysia. Sociodemographic data were obtained using validated questionnaires. Serological screening for leptospirosis was performed using an ELISA method and confirmed by microscopic agglutination test (MAT). Samples indeterminate and positive according to ELISA $(n=117)$ were sent for MAT testing. A MAT titer $\geq 100$ was considered positive evidence of exposure to leptospirosis. The overall seroprevalence of leptospirosis among the subjects was $16.2 \%$ (95\% confidence interval: 13.32, 19.15). The most common reaction obtained with the sera tested by MAT was against a strain of Leptospira spp. isolated from Terengganu (38.3\%) followed by $L$. biflexa serovar Patoc (35.2\%). In conclusion, the seroprevalence of leptospirosis among army personnel in Northeastern Malaysia is high.
\end{abstract}

\section{Keywords}

Seroprevalence, Leptospirosis, Army Personnel, Northeastern Malaysia

\section{Introduction}

Leptospirosis is a zoonotic disease that can be transmitted from animals to humans [1] [2]. Humans are usually the incidental hosts [3] [4]. The prevalence of 
leptospirosis varies among countries. In the Philippines, there are 147 cases per 100,000 people [5]. Furthermore, the seroprevalence of leptospirosis in Laos is reported to be $23.9 \%$ [6].

Leptospirosis is an occupational disease reported to affect soldiers in the UK and the former West Germany [7]. Army jobs are high-risk occupations for leptospirosis [8] [9] [10]; this is because army personnel perform operation and military exercise activities that bring them into contact with zoonotic reservoirs [7] [11] [12]. However, few studies worldwide indicate a risk of infections at training sites [10] [13].

Most studies on leptospirosis involving army personnel to date have focused on outbreak episodes rather than merely exposed personnel; thus, the literature on asymptomatic infection is sparse. Furthermore, few outbreaks involving military personnel have been reported worldwide [8] [9].

Enzyme-linked immunosorbent assays (ELISAs) are based on chemical reactions rather than live bacterial specimens. There is an ELISA that only reacts to one type of antibody (i.e., IgM, IgG, or IgA) that can help determine if the titer is of current or historical origin [14]. In the present study, the Pan Bio Leptospira IgM ELISA test (PanBio, Queensland, Australia) was used for the qualitative detection of IgM antibodies to Leptospira in sera. This ELISA can detect infections caused by several $L$. interrogans serovars including Hardjo, Copenhageni, Pomona, Madanesis, Australis, Kremastos, Nikolaevo, Celledoni, Canicola, Grippotyphosa, Swajzak, Djasima, and Tarrasovi [15].

The microscopic agglutination test (MAT) is the gold standard for confirming leptospirosis because of its high sensitivity and specificity compared to other currently available tests [16] [17]. This test is most appropriate for seroprevalence studies and is generally performed in reference laboratories. However, it is operator-dependent as well as difficult to perform, interpret, and maintain; therefore, the use of the MAT is limited, especially in developing countries where leptospirosis is endemic [18]. Therefore, the use of different tests in other studies depended on the availability of the test during the study period.

\section{Methods}

This cross-sectional study involved 616 army personnel in four camps in Northeastern Malaysia. Socio-demographic data were obtained using a validated questionnaire. Informed consent was obtained from all subjects.

Venous blood $(5 \mathrm{~mL})$ was taken from each subject for the qualitative detection of IgM antibodies against Leptospira by ELISA (Panbio, Queensland, Australia). A score of $<9$ units indicates a negative result or no detectable IgM antibodies, 9

- 11 units indicates an indeterminate result, and $>11$ units indicates a positive result and thus the presence of Leptospira-specific IgM antibodies. The samples were analyzed by trained laboratory personnel in the Microbiology Laboratory of Universiti Sains Malaysia.

The indeterminate and positive samples were subsequently sent to the Insti- 
tute for Medical Research (IMR) for the MAT. The samples were tested against the following 17 serovars: L. biflexa serovar Patoc, L. interrogans serovar Autumnalis, $L$. interrogans serovar Bataviae, $L$. interrogans serovar Canicola, $L$. interrogans serovar Celledoni, L. interrogans serovar Hardjobovis, L. interrogans serovar Icterohaemorrhagiae, $L$. borgpetersenii serovar Javanica, L. interrogans serovar Pomona, L. interrogans serovar Pyrogenes, L. interrogans serovar Hardjoprajitno, Leptospira spp. isolated from Melaka, Leptospira spp. isolated from Terengganu, Leptospira spp. isolated from Sarawak, L. interrogans serovar Copenhageni, L. interrogans serovar Australis, and L. interrogans serovar Lai. A MAT titer $\geq 100$ was considered evidence of exposure to leptospirosis [18] [19]. The seroprevalence of leptospirosis was calculated and presented as proportions and $95 \%$ confidence intervals (CIs).

\section{Results}

The majority of subjects were Malay males. Their mean (SD) age was 29.28 (7.15) years. The sociodemographic characteristics of the participants are shown in Table 1.

When a MAT titer $\geq 100$ was considered positive, the overall seroprevalence of leptospirosis was $16.2 \%$ (95\% CI: 13.32, 19.15) (Table 2). Table 3 shows the distribution of serovars determined according to positive MAT results among the 100 seropositive cases.

Table 1. Sociodemographic characteristics $(n=616)$.

\begin{tabular}{ccc}
\hline Variables & Frequency (\%) & Mean (SD) \\
\hline Age & & \\
Sex & $608(98.28(7.15)$ \\
Male & $8(1.3)$ \\
Female & \\
Race & $525(85.2)$ \\
Malay & $91(14.7)$ \\
Others &
\end{tabular}

Table 2. Seroprevalence of leptospirosis $(n=616)$.

\begin{tabular}{cccc}
\hline & Frequency & $(\%)$ & $95 \% \mathrm{CI}$ \\
\hline Positive & 100 & $(16.2)$ & $(13.32,19.15)$ \\
Negative & 516 & $(83.8)$ & $(80.85,86.68)$
\end{tabular}

Table 3. Serovar distribution for positive MAT (titer $\geq 100$ ) among 100 army personnel.

\begin{tabular}{ccc}
\hline Serovars tested & Frequency & $\%$ \\
\hline${ }^{*}$ Leptospira spp. isolated from Terengganu & 74 & 38.3 \\
L. biflexa serovar Patoc & 68 & 35.2 \\
L. interrogans serovar Celledoni & 11 & 5.7
\end{tabular}




\section{Continued}

\begin{tabular}{ccc}
\hline L. interrogans serovar Hardjobovis & 5 & 2.6 \\
L. interrogans serovar Australis & 4 & 2.1 \\
L. interrogans serovar Canicola & 4 & 2.1 \\
${ }^{\star}$ Leptospira spp. isolated from Sarawak & 4 & 2.1 \\
L. interrogans serovar Autumnalis & 3 & 1.6 \\
L. interrogans serovar Copenhageni & 3 & 1.6 \\
L. interrogans serovar Lai & 3 & 1.6 \\
${ }^{*}$ Leptospira spp. isolated from Melaka & 3 & 1.6 \\
L. interrogans serovar Pyogenes & 3 & 1.6 \\
L. interrogans serovar Bataviae & 2 & 1.0 \\
L. interrogans serovar Hardjoprajitno & 2 & 1.0 \\
L. borgpetersenii serovar Javanica & 2 & 1.0 \\
L. interrogans serovar Icterohaemorrhagiae & 1 & 0.5 \\
L. interrogans serovar Pomona & 1 & 0.5 \\
\hline
\end{tabular}

${ }^{\star}$ Local strain.

\section{Discussion}

The seroprevalence of leptospirosis varies among professions; it was also influenced by other factors such as region, weather, and climate [5] [20] [21] [22]. The seroprevalence of leptospirosis among army personnel in the present study was high (16.2\%) based on a MAT titer $\geq 100$. This finding was consistent with those of other local studies [20] [23]. Tan reports the seroprevalence of leptospirosis among afebrile Malaysian army personnel ranged from 13.0\% - 17.2\% using a sensitized erythrocyte lysis (SEL) test with a positive titer cut-off of $\geq 80$. Meanwhile, Supramaniam reports a slightly wider range of the seroprevalence $(12 \%-22 \%)$ in a similar population.

However, the seroprevalence of leptospirosis among army personnel in the present study was higher than in a previous study in Nepal, which reports the prevalence of cases confirmed by MAT to be 8\% [24]. Another seroprevalence study among military recruits following an outbreak after a training exercise in a jungle reports the seroprevalence of leptospirosis was $28 \%$ [9], this value may be higher than in the present study owing to the fact that their study population was symptomatic with fever and other symptoms suggestive of leptospirosis. Most outbreak studies involving army personnel to date have focused on symptomatic patients rather than merely exposed individuals; thus, the literature on asymptomatic infection is sparse.

In comparison to other occupational risk groups, the seroprevalence among army personnel in this study was lower than reported among civilian service workers. Using similar methods and MAT titer cut-off, Sulong et al. found the overall seroprevalence of leptospirosis among civilian service workers in Malay- 
sia to be $24.7 \%$ [25]. Studies in Madras, India and Singapore report very similar seroprevalence rates of $24.8 \%$ and $20.8 \%$, respectively [26] [27]. However, the seroprevalence among army personnel in the present study was higher than low-occupational-risk group (e.g., school teachers, housewives, and indoor workers), which was reported to range from $1.5 \%-9.4 \%$ [20].

The seroprevalence of leptospirosis among army personnel in the present study was higher than symptomatic patients in the general population. In a hospital-based cross-sectional study performed in Malaysia, the seroprevalence of leptospirosis among the general population was 8.4\% [28]. A study in India reports a very similar finding, in which the seroprevalence among high-occupation-risk subjects was higher than the general population [22].

The MAT is the gold standard for confirming leptospirosis. However, the cut-off was not standardized. Instead, the cut-off usually depends on the baseline of the community in a particular geographical area [19] and varies among laboratories [18]. In Malaysia, there is no consensus regarding a standard cut-off titer for the seroprevalence of leptospirosis in high-risk groups. However, a cut-off of $\geq 100$ is generally accepted [18] and frequently used in other seroprevalence studies [29] [30] [31]. Other researchers recommend a titer of $\geq 50$ for serosurveys in asymptomatic high-risk groups [32]. Accordingly, the seroprevalence of the subjects in the present study might be underestimated if other cut-offs were applied. Another study performed in Brazil using the MAT with different cut-offs $\geq 100, \geq 50$, and $\geq 25$ demonstrates seroprevalence rates of $18 \%, 23 \%$, and $30 \%$ respectively [33].

In this study, the most common reaction obtained with the sera tested by the MAT was against a strain of Leptospira spp. isolated from Terengganu, Malaysia (38.3\%) followed by L. biflexa serovar Patoc (35.2\%). The actual infecting pathogenic serovar is likely to have evolved from the local saprophytic strains and is unrelated to the pathogenic serovars included in the test panel. Therefore, the local endemic pathogenic serovars in this area need to be studied further.

Non-pathogenic L. biflexa serovar Patoc was the second most common serovar identified in this study. A study in Turkey reports a similar finding [34]. $L$. biflexa serovar Patoc was a saprophytic strain that cross-reacts with human antibodies generated by several pathogenic serovars in rare cases or perhaps with a strain that was currently unknown in the area concerned [16]. The finding of non-pathogenic serogroups was consistent with the notion that a finding of non-pathogenic serogroups suggests the circulation of other pathogenic serogroups that may not be included in that particular study [16]. Thus, this highlights the importance of validating MAT cut-offs for the specific epidemiological situation in which a seroprevalence survey was being performed.

The importance of identifying specific serogroups was prompted by the findings by previous studies suggesting distinct clinical features were associated with specific serogroups [35]. However, a more thorough long-term study rejected this hypothesis [36]. Several serovars were strongly associated with certain occupational risk groups [37]. However, these associations could not be demon- 
strated in the present study.

The importance of asymptomatic infection and subclinical presentation was not well understood, and efforts to determine their significance were limited [38]. However, it was generally believed that serovar-specific antibodies were protective, and that person will immune to re-infection by the same serovar if the concentration (i.e., titer) of specific antibodies was sufficiently high [16] [39]. In view of those findings, asymptomatic infections may play a role in population immunity (i.e., "herd immunity") against leptospirosis. Therefore, seroprevalence studies in high-risk groups may reflect exposure but not necessarily overt disease.

Severe complications may occur after the course of the illness in a small proportion of patients [40]. In unfortunate cases, there were clinical presentations of multiple organ involvement. Case fatality rates in different regions worldwide were reported to range from $<5 \%-30 \%$ [40]. Death remains significant and was mainly due to delayed diagnosis owing to a lack of infrastructure as well as adequate clinical suspiciousness [1]. Leptospirosis was recognized as an emerging potentially epidemic disease representing a significant public health challenge [41].

\section{Conclusion}

The seroprevalence of leptospirosis among army personnel in Northeastern Malaysia was $16.2 \%$. High seroprevalence of leptospirosis among the respondents indicated that army personnel were occupational risk groups for leptospirosis. The most common reaction obtained with the sera tested by the MAT was against a strain of Leptospira spp. isolated from Terengganu (38.3\%) followed by L. biflexa serovar Patoc (35.2\%). The findings from this study could be used for prevention and control of leptospirosis among high risk groups. The top management of the army should take all the practicable steps and appropriate measures to promote a safe and healthy workplace. Involvement of the top management can ensure the sustainability of the program. Good data from the seroprevalence study among the army personnel can help to demonstrate how serious the problem in the respective place.

\section{Acknowledgements}

The authors would like to express their sincere gratitude to Medical Division Army who gave the permission for this research and to all study participants. This study was funded by the Research University Grant (1001/PPSP/812106) and was ethically approved by the Ethics Committee of the Ministry of Health (NMRR-10-318-5389) and Research and Ethics Committee (Human) of Universiti Sains Malaysia (Reference no: USMKK/PPP/JEPeM [219.3. (03)]).

\section{Conflicts of Interest}

The authors declare no conflicts of interest regarding the publication of this paper. 


\section{References}

[1] Bharti, A.R., Nally, J.E., Ricaldi, J.N., Matthias, M.A., Diaz, M.M., Lovett, M.A., Levett, P.N., Gilman, R.H., Willig, M.R., Gotuzzo, E. and Vinetz, J.M. (2003) Leptospirosis: A Zoonotic Disease of Global Importance. The Lancet Infectious Diseases, 3, 757-771. https://doi.org/10.1016/S1473-3099(03)00830-2

[2] Vanasco, N.B., Schmeling, M.F., Lottersberger, J., Costa, F., Ko, A.I. and Tarabla, H.D. (2008) Clinical Characteristics and Risk Factors of Human Leptospirosis in Argentina (1999-2005). Acta Tropica, 107, 255-258. https://doi.org/10.1016/j.actatropica.2008.06.007

[3] Richardson, D.J. and Gauthier, J.L. (2003) A Serosurvey of Leptospirosis in Connecticut Peridomestic Wildlife. Vector-Borne and Zoonotic Diseases, 3, 187-193. https://doi.org/10.1089/153036603322662174

[4] Moore, G.E., Guptill, L.F., Glickman, N.W., Caldanaro, R.J., Aucoin, D. and Glickman, L.T. (2006) Canine Leptospirosis, United States, 2002-2004. Emerging Infectious Diseases, 12, 501-503. https://doi.org/10.3201/eid1203.050809

[5] Yanagihara, Y., Villanueva, S.Y., Yoshida, S., Okamoto, Y. and Masuzawa, T. (2007) Current Status of Leptospirosis in Japan and Philippines. Comparative Immunology, Microbiology \& Infectious Diseases, 30, 399-413. https://doi.org/10.1016/j.cimid.2007.05.003

[6] Kawaguchi, L., Sengkeopraseuth, B., Tsuyuoka, R., Koizumi, N., Akashi, H., Vongphrachanh, P., Watanabe, H. and Aoyama, A. (2008) Seroprevalence of Leptospirosis and Risk Factor Analysis in Flood-Prone Rural Areas in Lao PDR. The American Journal of Tropical Medicine and Hygiene, 78, 957-961. https://doi.org/10.4269/ajtmh.2008.78.957

[7] Johnston, J.H., Lloyd, J., McDonald, J. and Waitkins, S. (1983) Leptospirosis-An Occupational Disease of Soldiers. The Journal of the Royal Army Medical Corps, 129, 111-114.

[8] Katz, A.R., Sasaki, D.M., Mumm, A.H., Escamilla, J., Middleton, C.R. and Romero, S.E. (1997) Leptospirosis on Oahu: An Outbreak among Military Personnel Associated with Recreational Exposure. Military Medicine, 162, 101-104. https://doi.org/10.1093/milmed/162.2.101

[9] Russell, K.L., Montiel Gonzalez, M.A., Watts, D.M., Lagos-Figueroa, R.C., Chauca, G., Ore, M., Gonzalez, J.E., Moron, C., Tesh, R.B. and Vinetz, J.M. (2003) An Outbreak of Leptospirosis among Peruvian Military Recruits. The American Journal of Tropical Medicine and Hygiene, 69, 53-57. https://doi.org/10.4269/ajtmh.2003.69.53

[10] Payne, K.S., Klein, T.A., Otto, J.L., Kim, H.C., Chong, S.T., Ha, S.J., Gu, S.H., Jeong, J.H., Baek, L.J. and Song, J.W. (2009) Seasonal and Environmental Determinants of Leptospirosis and Scrub Typhus in Small Mammals Captured at a U.S. Military Training Site (Dagmar North), Republic of Korea, 2001-2004. Military Medicine, 174, 1061-1067. https://doi.org/10.7205/MILMED-D-00-3809

[11] Takafuji, E.T., Kirkpatrick, J.W., Miller, R.N., Karwacki, J.J., Kelley, P.W., Gray, M.R., McNeill, K.M., Timboe, H.L., Kane, R.E. and Sanchez, J.L. (1984) An Efficacy Trial of Doxycycline Chemoprophylaxis against Leptospirosis. The New England Journal of Medicine, 310, 497-500. https://doi.org/10.1056/NEJM198402233100805

[12] Corwin, A., Ryan, A., Bloys, W., Thomas, R., Deniega, B. and Watts, D. (1990) A Waterborne Outbreak of Leptospirosis among United States Military Personnel in Okinawa, Japan. International Journal of Epidemiology, 19, 743-748.

https://doi.org/10.1093/ije/19.3.743 
[13] Hadad, E., Pirogovsky, A., Bartal, C., Gilad, J., Barnea, A., Yitzhaki, S., Grotto, I., Balicer, R.D. and Schwartz, E. (2006) An Outbreak of Leptospirosis among Israeli Troops near the Jordan River. The American Journal of Tropical Medicine and Hygiene, 74, 127-131. https://doi.org/10.4269/ajtmh.2006.74.127

[14] Terpstra, W.J., Ligthart, G.S. and Schoone, G.J. (1985) ELISA for the Detection of Specific IgM and IgG in Human Leptospirosis. Journal of General Microbiology, 131, 377-385. https://doi.org/10.1099/00221287-131-2-377

[15] Winslow, W.E., Merry, D.J., Pirc, M.L. and Devine, P.L. (1997) Evaluation of a Commercial Enzyme-Linked Immunosorbent Assay for Detection of Immunoglobulin M Antibody in Diagnosis of Human Leptospiral Infection. Journal of Clinical Microbiology, 35, 1938-1942. https://doi.org/10.1128/JCM.35.8.1938-1942.1997

[16] WHO (2003) Human Leptospirosis: Guidance for Diagnosis, Surveillance and Control.

[17] Collins, R.A. (2006) Leptospirosis. The Biomedical Scientist.

[18] Plank, R. and Dean, D. (2000) Overview of the Epidemiology, Microbiology, and Pathogenesis of Leptospira spp. in Humans. Microbes and Infection, 2, 1265-1276. https://doi.org/10.1016/S1286-4579(00)01280-6

[19] WHO (2007) Leptospirosis: Laboratory Manual.

[20] Tan, D.S. (1973) Occupational Distribution of Leptospiral (SEL) Antibodies in West Malaysia. Medical Journal of Malaysia, 27, 253-257.

[21] El Jalii, I.M. and Bahaman, A.R. (2004) A Review of Human Leptospirosis in Malaysia. Tropical Biomedicine, 21, 113-119.

[22] Sharma, S., Vijayachari, P., Sugunan, A.P., Natarajaseenivasan, K. and Sehgal, S.C. (2006) Seroprevalence of Leptospirosis among High-Risk Population of Andaman Islands, India. The American Journal of Tropical Medicine and Hygiene, 74, 278-283. https://doi.org/10.4269/ajtmh.2006.74.278

[23] Supramaniam, V. (1979) Leptospirosis in the Malaysian Army. Malaysian Journal of Pathology, 2, 11-14.

[24] Myint, K.S., Murray, C.K., Scott, R.M., Shrestha, M.P., Mammen, M.P., Shrestha, S.K., Kuschner, R.A., Joshi, D.M. and Gibbons, R.V. (2010) Incidence of Leptospirosis in a Select Population in Nepal. Transactions of the Royal Society of Tropical Medicine and Hygiene, 104, 551-555. https://doi.org/10.1016/j.trstmh.2010.04.001

[25] Sulong, M.R., Shafei, M.N., Yaacob, N.A., Hassan, H., Daud, A., Mohamad, W.M.Z.W., Ismail, Z. and Abdullah, M.R. (2011) Risk Factors Associated with Leptospirosis among Town Service Workers. International Medical Journal, 18, 83-88.

[26] Chan, O.Y., Paul, D.R. and Sng, E.H. (1987) Leptospirosis among Abattoir Workers: A Serological Survey. Singapore Medical Journal, 28, 293-296.

[27] Ratnam, S., Everard, C.O., Alex, J.C., Suresh, B. and Thangaraju, P. (1993) Prevalence of Leptospiral Agglutinins among Conservancy Workers in Madras City, India. Journal of Tropical Medicine and Hygiene, 96, 41-45.

[28] Rafizah, A.A., Aziah, B.D., Azwany, Y.N., Imran, M.K., Rusli, A.M., Nazri, S.M., Nikman, A.M., Nabilah, I., Asma, H.S., Zahiruddin, W.M. and Zaliha, I. (2013) Risk Factors of Leptospirosis among Febrile Hospital Admissions in Northeastern Malaysia. Preventive Medicine, 57, S11-S13. https://doi.org/10.1016/j.ypmed.2012.12.017

[29] Goncalves, D.D., Teles, P.S., dos Reis, C.R., Lopes, F.M., Freire, R.L., Navarro, I.T., Alves, L.A., Muller, E.E. and de Freitas, J.C. (2006) Seroepidemiology and Occupational and Environmental Variables for Leptospirosis, Brucellosis and Toxoplasmo- 
sis in Slaughterhouse Workers in the Parana State, Brazil. The Revista do Instituto de Medicina Tropical de São Paulo, 48, 135-140. https://doi.org/10.1590/S0036-46652006000300004

[30] Swapna, R.N., Tuteja, U., Nair, L. and Sudarsana, J. (2006) Seroprevalence of Leptospirosis in High Risk Groups in Calicut, North Kerala, India. Indian Journal of Medical Microbiology, 24, 349-352. https://doi.org/10.4103/0255-0857.29418

[31] Velineni, S., Asuthkar, S., Umabala, P., Lakshmi, V. and Sritharan, M. (2007) Serological Evaluation of Leptospirosis in Hyderabad Andhra Pradesh: A Retrospective Hospital-Based Study. Indian Journal of Medical Microbiology, 25, 24-27. https://doi.org/10.4103/0255-0857.31057

[32] Shivakumar, S. and Krishnakumar, B. (2006) Diagnosis of Leptospirosis: Role of MAT. The Journal of the Association of Physicians of India, 54, 338-339.

[33] Maciel, E.A., de Carvalho, A.L., Nascimento, S.F., de Matos, R.B., Gouveia, E.L., Reis, M.G. and Ko, A.I. (2008) Household Transmission of Leptospira Infection in Urban Slum Communities. PLOS Neglected Tropical Diseases, 2, e154. https://doi.org/10.1371/journal.pntd.0000154

[34] Esen, S., Sunbul, M., Leblebicioglu, H., Eroglu, C. and Turan, D. (2004) Impact of Clinical and Laboratory Findings on Prognosis in Leptospirosis. Swiss Medical Weekly, 134, 347-352.

[35] Sehgal, S.C., Vijayachari, P., Smythe, L.D., Norris, M., Symonds, M., Dohnt, M., Korver, H., Kemp, H., Hartskeerl, R.A. and Terpstra, W.J. (2000) Lai-Like Leptospira from the Andaman Islands. Indian Journal of Medical Research, 112, 135-139.

[36] Levett, P.N., Branch, S.L., Whittington, C.U., Edwards, C.N. and Paxton, H. (2001) Two Methods for Rapid Serological Diagnosis of Acute Leptospirosis. Clinical and Diagnostic Laboratory Immunology, 8, 349-351. https://doi.org/10.1128/CDLI.8.2.349-351.2001

[37] Slack, A.T., Symonds, M.L., Dohnt, M.F. and Smythe, L.D. (2006) The Epidemiology of Leptospirosis and the Emergence of Leptospira borgpetersenii Serovar Arborea in Queensland, Australia, 1998-2004. Epidemiology and Infection, 134, 1217-1225. https://doi.org/10.1017/S0950268806006352

[38] Phraisuwan, P., Whitney, E.A., Tharmaphornpilas, P., Guharat, S., Thongkamsamut, S., Aresagig, S., Liangphongphanthu, J., Junthima, K., Sokampang, A. and Ashford, D.A. (2002) Leptospirosis: Skin Wounds and Control Strategies, Thailand, 1999. Emerging Infectious Diseases, 8, 1455-1459. https://doi.org/10.3201/eid0812.020180

[39] Ashford, D.A., Kaiser, R.M., Spiegel, R.A., Perkins, B.A., Weyant, R.S., Bragg, S.L., Plikaytis, B., Jarquin, C., De Lose Reyes, J.O. and Amador, J.J. (2000) Asymptomatic Infection and Risk Factors for Leptospirosis in Nicaragua. The American Journal of Tropical Medicine and Hygiene, 63, 249-254. https://doi.org/10.4269/ajtmh.2000.63.249

[40] WHO (2009) Estimating the Global Burden of Human Leptospirosis.

[41] Edwards, C.N. and Levett, P.N. (2004) Prevention and Treatment of Leptospirosis. Expert Review of Anti-Infective Therapy, 2, 293-298.

https://doi.org/10.1586/14787210.2.2.293 